\title{
ESTUDO DA COMPOSIÇÃO ÓTIMA DE DIFERENTES RESÍDUOS ORGÂNICOS PARA A PRODUÇÃO DE BIOGÁS
}

\author{
A. ZANETTI ${ }^{1}$, L. S. ARRIECHE ${ }^{2 *}$, D.J.M. SARTORI ${ }^{3}$ \\ ${ }^{1}$ Bolsista PIBIC, Universidade Federal do Espírito Santo \\ ${ }^{2}$ Universidade Federal do Espírito Santo, Centro Universitário Norte do Espírito Santo, \\ Departamento de Engenharias e Tecnologia. \\ ${ }^{3}$ Universidade Federal de São Carlos, Centro de Ciências Exatas e Tecnologia, Departamento de \\ Engenharia Química. \\ *E-mail para contato: leoarrieche@ @otmail.com
}

\begin{abstract}
RESUMO - O biogás é uma fonte renovável de energia constituída principalmente de metano, componente relevante na equivalência em termos de conteúdo energético de um dado volume de biogás em relação a outros tipos de combustíveis. Esse trabalho visou estudar a composição ótima, em termos de uma relação específica de carbono e nitrogênio, a partir de diferentes resíduos gerados por indústrias para otimizar a produção de biogás. Para atingir esse objetivo associou-se a casca de cacau com outros resíduos de indústrias alimentícias, e otimizou-se a composição de resíduos tendo em vista como restrição a relação recomendada de nitrogênio/carbono. Obteve-se por meio de programação linear a composição de resíduos que foi empregada em experimentos. O estudo foi importante para a melhor inserção do biogás como uma fonte energética renovável no mercado brasileiro e para o desenvolvimento sustentável da região norte do Espirito Santo.
\end{abstract}

\section{INTRODUÇÃO}

A intensa geração de resíduos das agroindústrias, dos esgotos domésticos e da pecuária têm provocado sérios danos ambientais como contaminação de solo e água (Campani et al, 2009). O Brasil, por exemplo, é um grande produtor agrícola que se sustenta em cultivos como o café, diversas frutas, cana de açúcar, soja, milho e outros, e consequentemente gera uma grande quantidade de resíduos (Campani et al, 2009). Dessa forma, diante a necessidade de reduzir os impactos ambientais e gerar fontes energéticas aliados com a disponibilidade de nutrientes em resíduos, muitos estudos estão sendo direcionados à conversão deles em produtos comerciais pelo emprego da biomassa.

A biomassa, em termos mundiais, fornece em torno de $54 \mathrm{GW}$ de energia elétrica, em que a maior participação provém dos Estados Unidos e da União Européia. A energia obtida provém da transformação de resíduos orgânicos em biocombustíveis como o bioálcool, o biodiesel e o biogás (PRATI, 2010). Os países que usam o biogás utilizam-o para obter energia elétrica, calor, ou até mesmo para combustível veicular em que $1 \mathrm{~m}^{3}$ de biometano, biogás purificado, com reduzida concentração de dióxido de carbono, tem poder calorífico de cerca de 1 L de gasolina. A 
Alemanha é o país com maior capacidade instalada, 1,7 GW de energia, em produção de biogás, e apresenta em torno de 4700 usinas (WAELKENS, 2011).

De acordo com a Agência Nacional de Energia Elétrica (Aneel), no Brasil existem algumas usinas que produzem energia por meio do biogás, totalizando uma capacidade instalada de 80,66 MW (Aneel). Essas usinas, em geral, utilizam resíduos sólidos urbanos e resíduos agropecuários para a obtenção desse combustível. Por exemplo, a usina termelétrica Bandeirantes emprega o biogás advindo de aterro sanitário e produz energia elétrica com potência instalada de $22 \mathrm{MW}$ (Bordin, 2011).

A partir da degradação biológica anaeróbica de matéria orgânica, processo que digere proteínas, polissacarídeos, lipídeos e ácidos nucléicos, obtém-se o biogás. Esse combustível é constituído principalmente de metano e de dióxido de carbono, podendo apresentar também nitrogênio, oxigênio, hidrogênio e sulfureto de hidrogênio (BRITES e GAFEIRA, 2007).

Os responsáveis pelo processo de geração de biogás são as bactérias. Por isso, diversas variáveis influenciam na digestão anaeróbia, como: teor de água, $\mathrm{pH}$ e a alcalinidade, estado físico dos resíduos, temperatura, taxa de oxigenação, e os nutrientes. Esse último fornece carbono, nitrogênio e sais orgânicos para as bactérias. (BRITES E GAFEIRA, 2007). Logo, a composição dos resíduos utilizados influencia diretamente no teor de metano produzido. A relação recomendada de carbono e nitrogênio deve estar compreendida na faixa de 20:1 a 30:1 para maximizar a produção de biogás (VISWANATH et al, 1992).

A finalidade deste trabalho consistiu em estudar a composição ótima, em termos de uma relação específica de carbono e nitrogênio, a partir de diferentes resíduos gerados por indústrias e assim otimizar a produção de biogás. Para atingir este objetivo, foram realizados: estudo de possíveis resíduos potenciais na região, aplicação da programação linear a fim de obter a composição ótima de resíduos, preparo da massa residual formada pela casca de cacau com outros resíduos de indústrias alimentícias, caracterização granulométrica do resíduo por meio de análises de imagens das partículas, e também a condução de testes de geração de biogás.

\section{MATERIAIS}

Os experimentos requereram os seguintes materiais: kitassatos, rolhas, mangueiras de silicone, uma caixa luminosa, a casca do cacau, da laranja e da banana, provetas, água, suportes, bacias, e máquina fotográfica. A caixa luminosa para aquisição de imagens foi montada com madeira de pinos, chapa acrílica, lâmpadas, soquetes, fios elétricos, apresenta $30 \mathrm{~cm}$ de comprimento e largura, e $10 \mathrm{~cm}$ de altura.

\section{METODOLOGIA}

\subsection{Aplicações da programação linear}

Programação linear é uma técnica matemática que permite calcular uma solução ótima para certo tipo de problema, ou seja, visa propor um método a fim de maximizar a função objetivo no processo que se está estudando. Neste caso, objetiva-se por meio do uso dessa ferramenta, a determinação da melhor composição de uma mistura de resíduos para a produção de biogás, que apresente a relação específica de carbono e nitrogênio entre 20:1 e 
30:1. O sistema linear desenvolvido foi baseado na composição de carbono e nitrogênio de cada resíduo, empregado na mistura, como restrição. Determinou-se que os ensaios de geração de biogás empregassem três tipos de resíduos diferentes que totalizassem uma massa de 100 gramas, e assim de uma forma geral o sistema linear definido foi:

$$
\left\{\begin{array}{l}
m 1+m 2+m 3=100 g \\
a * m 1+b * m 2+c * m 3=m C \\
d * m 1+e * m 2+f * m 3=m N
\end{array}\right.
$$

Os valores $m_{1}, m_{2}$ e $m_{3}$ são as massas de cada resíduo, $a, b$ e $c$ são os percentuais de carbono, e $d$, e e $f$ são os percentuais de nitrogênio, respectivos aos resíduos 1,2 e 3 . A variável $m C$ diz respeito à massa total de carbono e $m N$ à massa total de nitrogênio contida na mistura dos resíduos.

\subsection{Preparo da massa residual com um diâmetro de partícula representativo}

O tamanho das partículas de um composto orgânico é um fator importante na produção de biogás porque, de acordo com a literatura, quanto menor a unidade da partícula, maior será a área da superfície específica e, portanto, a decomposição será mais rápida se comparada a uma partícula de menor área. O diâmetro equivalente das partículas foi medido através da análise de imagens. As partículas foram reduzidas com o auxílio de um liquidificador.

\subsection{Acréscimos de água para a decomposição das partículas}

O teor de umidade associado à amostra de partículas orgânicas influencia em sua decomposição e consequentemente na produção de biogás. Assim, para cada amostra utilizada nos experimentos foram adicionados $200 \mathrm{~mL}$ de água para gerar uma maior taxa de produção de biogás.

\subsection{Análises de imagens}

A partir das análises de imagens, foi possível obter informações a respeito da caracterização das partículas orgânicas, assim como os diâmetros, normalmente conhecidos como diâmetros de Feret, característica geométrica de sua feição bidimensional (área projetada), que influenciam na produção do biogás. Fotos digitais foram adquiridas de uma amostra representativa de partículas, que foram selecionadas aleatoriamente.

Estas partículas foram dispostas na superfície luminosa para aquisição de imagens. Por meio do programa computacional denominado ImageJ (criado e disponibilizado para pesquisa pela Universidade de São Paulo - USP), foram realizadas análises do diâmetro da casca de cacau das amostras preparadas para a produção do biogás. Para a realização da análise de imagem selecionase uma foto das partículas, altera-se a resolução das imagens para oito bits. Observa-se a distância lateral da imagem por meio da régua milimétrica colocada próxima às partículas, no instante da captura da foto. Assim, ajusta-se o limiar de escala de cinza de modo a aumentar o contraste entre as partículas e o fundo da imagem. Posteriormente, realiza-se a calibração utilizando-se a medida encontrada na régua milimétrica e por fim analisam-se as partículas. A imagem já analisada apresenta as partículas enumeradas. Para cada partícula enumerada obtêm-se os seguintes 
parâmetros:

- Área (Ar.): Área projetada selecionada das partículas, em $\mathrm{cm}^{2}$;

- Perímetro (Per.): O comprimento do limite da área projetada selecionada, em cm;

- O diâmetro de Feret (Fer.): A distância mais longa entre quaisquer dois pontos ao longo do limite de seleção, também conhecido como diâmetro calibrador máximo. As coordenadas de início do diâmetro de Feret (Fer.X e Fer.Y) também são exibidas;

- Diâmetro Equivalente $\left(D_{e}\right)$ : $O$ diâmetro da esfera equivalente e de mesma área projetada medida. A partir do diâmetro equivalente pode-se calcular o diâmetro de Sauter $\left(\mathrm{d}_{\mathrm{ps}}\right)$ que é o diâmetro médio de partícula dado pela Equação 4, onde $\mathrm{x}_{\mathrm{i}}$ é a distribuição de frequência, n o número de partícula e $\mathrm{D}_{\mathrm{i}}$ é o diâmetro equivalente:

$$
d_{p s}=\frac{1}{\sum_{i=1}^{n}\left(x_{i} / D_{i}\right)}
$$

- Relação de aspecto: Uma maneira de descrever a forma das partículas é a relação de aspecto (AR). O valor de AR é o mesmo que o valor do grau de alongamento (Al) que mede a razão do diâmetro circunscrito (dc) pelo inscrito (di), obtidos pela projeção da sombra da partícula sobre um plano em repouso;

- Esfericidade: A partir do grau de alongamento determina-se o grau de esfericidade, um índice que mensura o quão o formato da partícula se aproxima ao formato de uma esfera. Quanto mais próximo o grau de esfericidade estiver de um, mais esférica será a partícula. Assim, o grau de esfericidade pode ser dado pela Equação 5 (PEÇANHA E MASSARINI, 1986):

$$
\Phi=\frac{1}{A l}
$$

\subsection{Montagens de aparelhos para o recolhimento do biogás}

O armazenamento das amostras foi realizado em um kitassato, no qual uma rolha de borracha foi inserida para impedir o escape do biogás para o ambiente. Uma proveta foi preenchida com água e invertida numa bacia também com esse líquido. Uma das extremidades de um tubo de silicone foi colocada no interior da proveta e a outra foi conectada ao kitassato como pode ser visualizado na Figura 1:

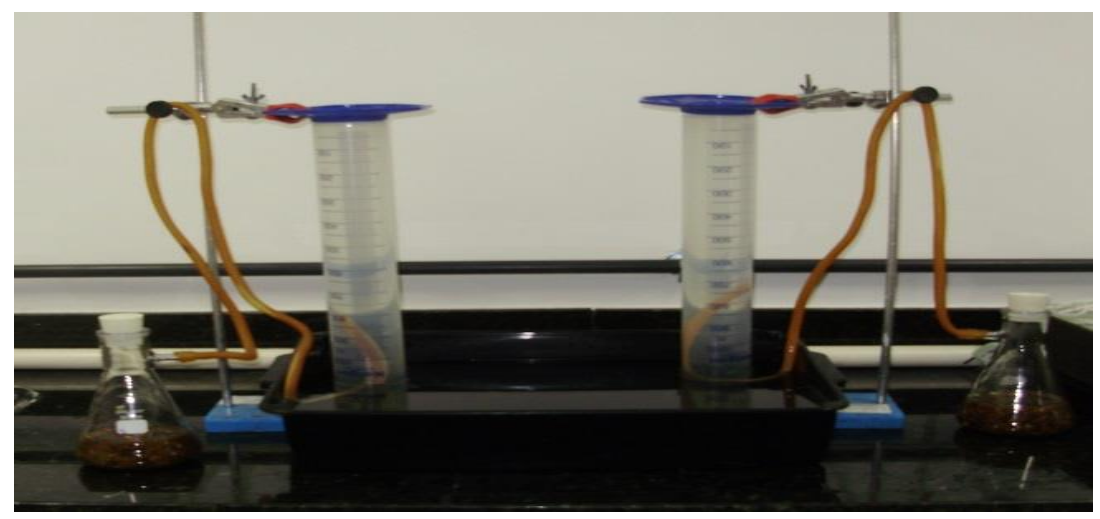

Figura 1 - Sistemas montados com os kitassatos para a coleta do biogás. 
Os experimentos foram realizados de acordo com os resultados da programação linear e se dividiram em quatro. No primeiro e segundo experimento foram utilizados a casca do cacau e mais dois resíduos com quantidades determinadas pela progamação para relação específica de carbono e nitrogênio 30:1, em massa. No terceiro utilizou-se o outro extremo da relação específica de carbono e nitrogênio que atendesse o sistema linear. Por fim, o quarto experimento foi realizado apenas com a casca de cacau.

\section{RESULTADOS}

\subsection{Programação linear}

Por meio da análise da composição de resíduos agroindustriais potenciais na região Norte do Espirito Santo optou-se pelo emprego da casca da laranja, casca da banana e a casca do cacau para a geração do biogás em que se priorizou a maior quantidade possível do último resíduo, tendo em vista a relação carbono e nitrogênio $(\mathrm{C} / \mathrm{N})$ entre 20 e 30. De acordo com a Embrapa têm-se os seguintes dados fornecidos pela Tabela 1:

Tabela 1- Composição dos resíduos em percentuais de nitrogênio e carbono

\begin{tabular}{c|c|c|c}
\hline Resíduo & Nitrogênio (\%) & Carbono (\%) & C/N \\
\hline Casca de cacau & $1,3(g)$ & $49,4(c)$ & 38 \\
\hline Casca de laranja & $42,5(b)$ & $1(f)$ & 40,5 \\
\hline Casca de banana & $1,9(e)$ & $40,5(a)$ & 21,3 \\
\hline
\end{tabular}

A partir dos dados da Tabela 1 resolveu-se, de forma geral, o sistema linear constituído pelas equações 1,2 e 3, em que o resíduo 1 é a casca de banana, o resíduo 2 é proveniente da laranja, e o resíduo 3 é a casca do cacau e obtiveram-se as massas dos resíduos em função das massas totais de carbono e nitrogênio:

$$
\left\{\begin{array}{l}
m 1=-4,4051 m C+101,3224 m N+85,8852 \\
m 2=-8,8107 m C-130,6912 m N+605,1625 \\
m 3=13,2159 m C+29,3688 m N-591,0478
\end{array}\right.
$$

O sistema linear acima descrito é indeterminado e dependente das variáveis $m N$ e $m C$. A Tabela 2 apresenta possíveis soluções que respeitam a relação específica de carbono e nitrogênio entre 20:1 e 30:1. É importante salientar que não foi possível obter soluções que atendessem o sistema para relações de $\mathrm{C} / \mathrm{N}$ abaixo de 23:1. Por isso, o terceiro experimento foi montado de acordo com as quantidades de resíduo que fornecem a razão 23:1. 
Tabela 2 - Possíveis soluções para o sistema linear estudado

\begin{tabular}{c|c|r|r|r|r}
\hline Razão C/N & $\begin{array}{l}\text { Massa de } \\
\text { nitrogênio } \\
\text { (gramas) }\end{array}$ & $\begin{array}{l}\text { Massa de } \\
\text { carbono } \\
\text { (gramas) }\end{array}$ & $\begin{array}{l}\text { Massa de } \\
\text { m1 } \\
\text { (gramas) }\end{array}$ & $\begin{array}{l}\text { Massa de } \\
\text { m2 } \\
\text { (gramas) }\end{array}$ & $\begin{array}{l}\text { Massa de } \\
\text { m3 } \\
\text { (gramas) }\end{array}$ \\
\hline $\mathbf{2 3 : 1}$ & 1,800 & 41,40 & 85,89 & 5,153 & 8,954 \\
\hline $\mathbf{2 4 : 1}$ & 1,750 & 42,00 & 78,18 & 6,401 & 15,41 \\
\hline $\mathbf{2 7 : 1}$ & 1,600 & 43,20 & 15,43 & 57,70 & 26,86 \\
\hline $\mathbf{2 8 : 1}$ & 1,500 & 42,00 & 39,07 & 52,85 & 8,073 \\
\hline $\mathbf{3 0 : 1}$ & 1,500 & 45,00 & 39,64 & 12,64 & 47,72 \\
\hline
\end{tabular}

\subsection{Análises de imagens}

A análise de imagens das partículas empregadas nos experimentos faz uma caracterização granulométrica que pode ser exemplificada pela Figura 2 e observada pela Tabela 3:

Tabela 3-Caracterização granulométrica amostral de partículas dos resíduos

\begin{tabular}{|c|c|c|c|c|c|c|c|c|c|c|}
\hline Resíduo & & $\begin{array}{l}\text { Ár. } \\
\left(\mathbf{c m}^{2}\right)\end{array}$ & $\begin{array}{l}\text { Per. } \\
\text { (cm) }\end{array}$ & $\begin{array}{l}\text { Fer. } \\
\text { (cm) }\end{array}$ & $\begin{array}{l}\text { Fer.X } \\
\text { (cm) }\end{array}$ & $\begin{array}{l}\text { Fer.Y } \\
\text { (cm) }\end{array}$ & $\begin{array}{l}\mathbf{A R} \\
(-)\end{array}$ & $\begin{array}{l}\text { De } \\
\text { (cm) }\end{array}$ & $\Phi$ & $\begin{array}{l}D_{\text {ps }} \\
(\mathbf{c m})\end{array}$ \\
\hline \multirow{2}{*}{$\begin{array}{c}\text { Casca } \\
\text { de } \\
\text { Cacau }\end{array}$} & Média & $\begin{array}{c}0,081 \\
4\end{array}$ & $\begin{array}{c}0,90 \\
5\end{array}$ & $\begin{array}{c}0,29 \\
1\end{array}$ & 5,03 & 3,86 & $\begin{array}{c}1,55 \\
4\end{array}$ & 0,133 & $\begin{array}{c}0,71 \\
5\end{array}$ & \multirow[b]{2}{*}{$\begin{array}{c}0,010 \\
9\end{array}$} \\
\hline & $\begin{array}{l}\text { Desvio } \\
\text { Padrão }\end{array}$ & 0,113 & 1,13 & $\begin{array}{c}0,32 \\
8\end{array}$ & 2,43 & 1,43 & $\begin{array}{c}0,54 \\
4\end{array}$ & $\begin{array}{c}0,091 \\
6\end{array}$ & $\begin{array}{c}0,21 \\
7\end{array}$ & \\
\hline \multirow{2}{*}{$\begin{array}{c}\text { Casca } \\
\text { de } \\
\text { Laranja }\end{array}$} & Média & 0,065 & $\begin{array}{c}0,45 \\
2\end{array}$ & $\begin{array}{c}0,14 \\
7\end{array}$ & 4,111 & 3,508 & 1,560 & 0,109 & 0,742 & \multirow[b]{2}{*}{0,0152} \\
\hline & $\begin{array}{l}\text { Desvio } \\
\text { Padrão }\end{array}$ & 0,149 & 1,02 & $\begin{array}{c}0,32 \\
5\end{array}$ & 2,650 & $\begin{array}{c}1,2042 \\
74\end{array}$ & 0,706 & 0,0956 & 0,249 & \\
\hline \multirow{2}{*}{$\begin{array}{c}\text { Casca } \\
\text { de } \\
\text { Banana }\end{array}$} & Média & 0,474 & $\begin{array}{c}2,83 \\
5\end{array}$ & $\begin{array}{c}0,94 \\
7\end{array}$ & 3,909 & 2,74 & 2,07 & 0,324 & 0,603 & \multirow[b]{2}{*}{0,170} \\
\hline & $\begin{array}{l}\text { Desvio } \\
\text { Padrão }\end{array}$ & 0,734 & $\begin{array}{c}2,68 \\
8\end{array}$ & $\begin{array}{c}0,73 \\
8\end{array}$ & 2,56 & 1,56 & 1,17 & 0,233 & 0,250 & \\
\hline
\end{tabular}




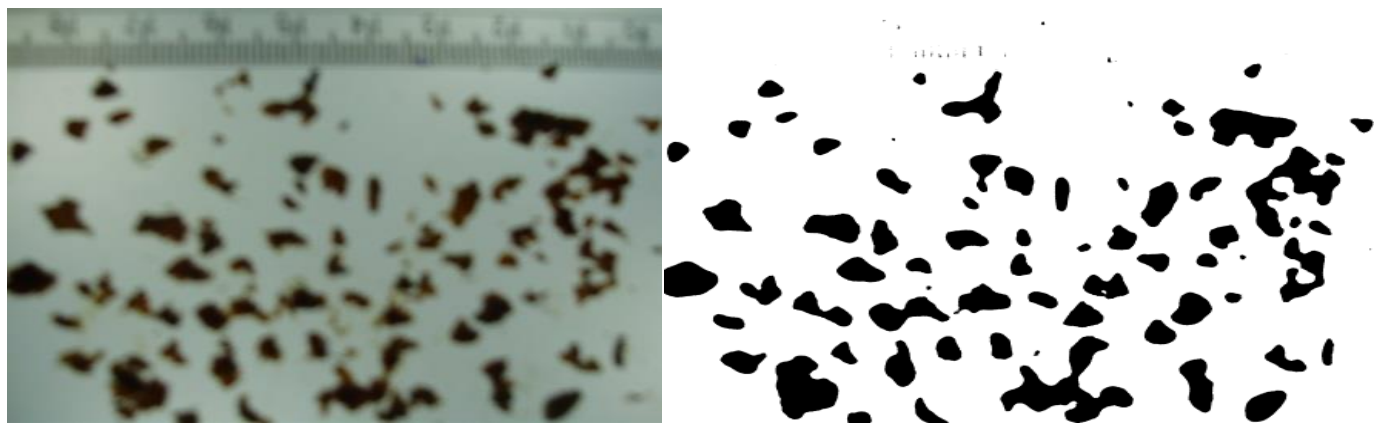

Figura 2: Fotos das partículas da casca de cacau antes e depois da análise de imagens.

\subsection{Produções de biogás}

Os quatro experimentos foram realizados, à temperatura ambiente, $25^{\circ} \mathrm{C}$, empregandose aproximadamente 100 gramas de resíduo. As quantidades produzidas em mililitros podem ser visualizadas na Figura 3. Para estes experimentos típicos, a biodigestão ocorreu com a própria microbiota presente na casca dos frutos.

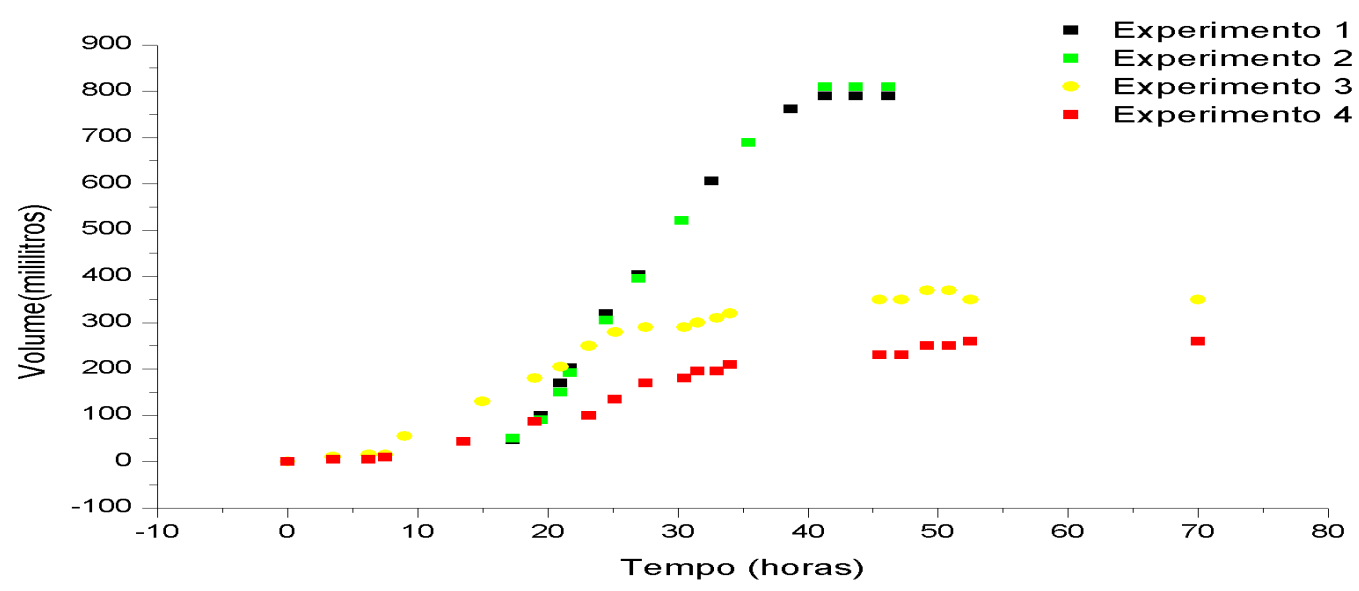

Figura 3 - Volume de biogás em função do tempo correspondente aos quatro experimentos.

Nos experimento 1 e 2 utilizaram-se as massas de cada resíduo, casca de banana, laranja e cacau respectivas a razão de $\mathrm{C} / \mathrm{N}$ de 30:1 expressas na Tabela 2. As réplicas se comportaram com produção e taxas de geração de biogás similares, que foram obtidas pelo programa OriginPro $8 \circledR$. No primeiro, o maior volume produzido foi de $790 \mathrm{~mL}$ em 43 horas, e a maior taxa foi de 44,6 mL/hr em 21 horas. No segundo, produziu-se $810 \mathrm{~mL}$ em 41 horas, e a taxa máxima foi de $48,5 \mathrm{~mL} / \mathrm{hr}$ em 21,5 horas. O terceiro experimento 3 foi promovido de acordo com a relação de $\mathrm{C} / \mathrm{N}$ de $23: 1$, em que a casca da banana foi o resíduo com maior quantidade mássica. O volume de biogás obtido foi de $370 \mathrm{~mL}$ em 50,84 horas, e a maior taxa de produção foi de $17,67 \mathrm{~mL} / \mathrm{hr}$ em 23,17 horas. Por fim, no quarto experimento empregou-se apenas a casca de cacau, e obteve-se a menor quantidade de biogás, $260 \mathrm{~mL}$. Em termos da taxa, também apresentou a menor, $16,26 \mathrm{~mL} / \mathrm{hr}$ em 25,17 horas. Vale salientar que as taxas máximas, nos quatro experimentos, ocorreram em quantidade de tempo aproximadas, embora seus valores sejam divergentes quando se comparam os primeiros com os últimos. 


\section{CONCLUSÕES}

Pôde-se notar que a geração de biogás foi mais efetiva para a casca de cacau associada à casca de laranja, e de banana já que se observa a produção de biogás decrescente do experimento 1 ao 4 . A relação de $\mathrm{C} / \mathrm{N}$ realmente influencia na geração de biogás como afirma a literatura, e dados os resultados, a maior quantidade produzida corresponde à relação 30:1 no qual se empregou a maior massa da casca de cacau. De acordo com a Tabela 3, foi possível utilizar partículas de resíduos reduzidas o suficiente para gerar uma quantidade expressiva de biogás que pode ser notada, por exemplo, pelos baixos valores de diâmetro de Sauter. Os métodos foram apropriados porque foi possível obter resultados que atingiram o objetivo deste trabalho. O esquema do kitassato foi adequado para o recolhimento do biogás, pois apresentaram um bom nível de vedação.

\section{AGRADECIMENTOS}

Ao Programa Institucional de Bolsas de Iniciação Científica (PIBIC/UFES) pelo auxílio financeiro.

\section{REFERÊNCIAS}

BORDIN, F. S. Desenvolvimento de combustível modelo para estudo da combustão de biogás produzido na degradação anaeróbia de resíduos sólidos urbanos. 21p. (Monografia- Obtenção de título de Engenheiro Elétrica)- Universidade Federal do Rio Grande do Sul, Porto Alegre, 2011.

BRITES, O. ; GAFEIRA, T. Biogás. Faculdade de Ciências e Tecnologia, Universidade de Coimbra, Coimbra, 2007.

CAMPANI, D. B.; SCHNEIDER , P. S.; XAVIER, F. M. Determinação do poder calorífico do biogás gerado em aterros sanitários. 2009. III Congresso interamérico de resíduos sólidos de AIDIS. Porto Alegre, RS.

PEÇANHA, R. P., MASSARANI, G. Dimensão Característica e Forma de Partículas. Anais do XIV Encontro sobre Escoamento em Meios Porosos, Campinas, p.302-312, 1986.

PRATI, L. Geração de energia elétrica a partir do biogás gerado por biodigestores. (Monografia-Obtenção de título de Engenheiro Eletricista). 83p. Universidade Federal do Paraná, Curitiba, 2010.

VISWANATH, P.; DEVI, S.S.; NAND, K. Anaerobic Digestion of Fruit and Vegetable Processing Wastes for Biogas Production. Central Food Technological Research Institute, India,1992.

WAELKENS, B. E.; Sternad W. Potencial de otimização da produção de biogás gerado por uma digestão anaeróbia em ETEs. Revist a AIDIS de Ingeniería y Ciencias ambientales: Investigación, desarrollo y práctica. Vol. 4, No. 1, 65 - 75, 2011.

(®) OriginLab, Inc. 